\title{
O TERRITÓRIO NA CONSTITUIÇÃO DA REPÚBLICA PORTUGUESA (1976-2005) Dos preceitos fundadores às políticas de território do futuro
}

\author{
João Ferrão \\ Instituto de Ciências Sociais da Universidade de Lisboa (ICS-UL), Lisboa, Portugal
}

Resumo Este texto analisa a relação território - Constituição da República Portuguesa (CRP) a partir de três questões: (i) de que forma é o "território" considerado na versão originária da CRP (1976)?; (ii) qual a evolução ocorrida desde então até à versão em vigor em 2016 (aprovada em 2005)?; (iii) em que medida condiciona a atual CRP a formulação e execução de uma nova geração de políticas de território? A comparação das versões de 1976 e 2005 da Constituição permite identificar nove alterações mais relevantes, com destaque para a crescente "europeização" de princípios e conceitos e para a emergência do ordenamento do território como política pública autónoma. A Constituição em vigor, apesar de algumas limitações, não parece constituir um obstáculo à formulação de uma nova geração de políticas de território mais eficientes, democráticas e justas, embora a atual organização político-administrativa condicione a participação das várias entidades públicas no desenho e implementação dessas políticas.

Palavras-chave: Constituição, território, organização político-administrativa do território, ordenamento do território, políticas de território.

Abstract This paper analyses the relationship between territorial issues and the Constitution of the Portuguese Republic (CRP) from three standpoints: (i) how is territory considered in the original 1976 version of the CRP?; (ii) what lasting changes did the 2005 revision make?; and (iii) to what extent is the current CRP affecting the design and implementation of a new generation of territorial policies? A comparison of the 1976 and 2005 texts identifies nine main changes, including the growing "Europeanisation" of a number of key principles and concepts and the emergence of spatial planning as an autonomous public policy. Despite its shortcomings, the current version of the Constitution does not seem to be an obstacle to the formulation of a new generation of more efficient and democratic and fairer territorial policies. However, the current political-administrative organisation influences the participation of different public entities in the design and implementation of those policies.

Keywords: Constitution, territory, political and administrative territorial organisation, spatial planning, territorial policies.

Résumé Ce texte analyse la relation territoire-Constitution de la République Portugaise (CRP) à partir de trois questions: (i) comment le " territoire " est-il considéré dans la version originale de la CRP (1976) ? ; (ii) quelle a été son évolution jusqu'à la version en vigueur en 2016 (adoptée en 2005)? ; (ii) dans quelle mesure la CRP actuelle conditionne la formulation et la mise en œuvre d'une nouvelle génération de politiques territoriales ? La comparaison des deux versions de la Constitution (1976 et 2005) permet d'identifier neuf changements majeurs, comme l'" européisation " de certains principes et concepts et l'émergence de l'aménagement du territoire en tant que politique publique autonome. En dépit de certaines limitations, la Constitution en vigueur ne semble pas être un obstacle à la formulation d'une nouvelle génération de politiques plus efficaces, plus démocratiques et plus justes, bien que l'organisation politico-administrative actuelle limite la participation des diverses entités publiques à la conception et à la mise en œuvre de ces politiques.

Mots-clés: Constitution, territoire, organisation politique et administrative du territoire, aménagement du territoire, politiques territoriales.

Resumen En este texto se analiza la relación territorio - Constitución de la República Portuguesa (CRP) a partir de tres cuestiones: (i) ¿cómo es el "territorio" tomado en consideración en la versión original de la CRP (1976) ?; (ii) ¿que evolución ocurrió desde entonces hasta la versión en vigor en 2016 (aprobada en 2005) ?; (iii) ¿hasta qué punto la versión actual de la CRP condiciona la formulación y la implementación de una nueva generación de políticas territoriales? La comparación de las versiones de 1976 y 2005 de la Constitución identifica nueve cambios más significativos, de que destacamos la creciente "europeización" de diversos principios y conceptos y 
la emergencia del ordenamiento territorial como una política pública autónoma. La Constitución vigente, a pesar de algunas limitaciones, no parece ser un obstáculo a la formulación de una nueva generación de políticas más eficaces, democráticas y justas, aunque la actual organización político-administrativa condicione la participación de diversas entidades públicas en el diseño e implementación de las políticas.

Palabras-clave: Constitución, territorio, organización política y administrativa del territorio, ordenamiento territorial, políticas territoriales.

\section{Introdução}

Este texto centra-se na relação território - Constituição da República Portuguesa (CRP), analisando-a a partir de três questões: (i) de que forma é o "território" considerado na versão originária da CRP (1976)?; (ii) qual a evolução ocorrida desde então até à versão em vigor em 2016 (aprovada em 2005)?; (iii) em que medida condiciona a atual CRP a formulação e execução de uma nova geração de políticas de território? A resposta a estas três questões permite identificar as questões que os deputados da Assembleia da República consideraram pertinente introduzir em contextos sociopolíticos e temporais distintos no domínio em análise e esclarecer até que ponto os novos conteúdos entretanto aprovados favorecem, obstaculizam ou são neutros em relação ao desenho de novas políticas de território, tanto explícitas como implícitas.

\section{O “território" na Constituição da República Portuguesa de 1976 (CRP76)}

A versão originária da Constituição da República Portuguesa, aprovada em 2 de abril de 1976, inclui diversas menções explícitas, embora dispersas, ao "território". Essas referências podem ser agregadas em torno de quatro grandes desígnios:

a) O território como elemento-chave da soberania nacional

Nos princípios fundamentais, a Constituição de 1976 consagra o artigo 5.ำ ao "território", identificando a base geográfica do país nas suas componentes tanto terrestre (espaço definido no continente europeu e arquipélagos dos Açores e da Madeira) como marítima (águas territoriais e fundos marinhos). Existia ainda uma menção ao estatuto particular do território de Macau. Este artigo, ao sublinhar a eventualidade de retificação de fronteiras no n. .2 , tem a curiosidade de revelar que esta não é uma questão fechada, ficando por esclarecer se essa possibilidade se aplica à fronteira terrestre (Olivença?), à marítima (zona económica exclusiva?) ou a ambas.

Ainda no âmbito dos princípios fundamentais, merece realce o artigo 6.․ㅡ (estado unitário), que consagra a autonomia das autarquias locais e a descentralização democrática da administração pública (n. - 1) e reconhece o estatuto 
político-administrativo próprio das regiões autónomas no que diz respeito aos arquipélagos dos Açores e da Madeira.

O conceito de território como elemento-chave da soberania nacional é confirmado na parte III ("Organização do poder político"), no título $X$, relativo às forças armadas, através do artigo 273. ․ n.. 1 , onde se refere que "As Forças Armadas Portuguesas garantem a independência nacional, a unidade do estado e a integridade do território."

O território como elemento constitutivo da soberania nacional surge, assim, bem destacado em torno da trilogia "espaço delimitado por fronteiras - organização político-administrativa - papel das forças armadas".

b) O território no contexto dos direitos e deveres fundamentais

O segundo grande desígnio a que o território surge associado diz respeito aos direitos e deveres fundamentais. Na parte I da Constituição, relativa aos direitos e deveres fundamentais, existem diversas referências explícitas ao "território".

No título I ("Princípios gerais"), artigo 13. ("Princípio da igualdade"), n.․․ 2, estabelece-se que "Ninguém pode ser privilegiado, beneficiado, prejudicado, privado de qualquer direito ou isento de qualquer dever" em razão de diversos fatores, entre eles o "território de origem". A interpretação e a aplicação deste princípio, que hoje poderíamos designar "princípio da justiça espaci$\mathrm{al}^{\prime \prime}$, levantam questões sensíveis do ponto de vista do seu âmbito de incidência, da definição das condições de acesso a serviços básicos de interesse comum ou, ainda, dos modos de garantir a sua efetiva concretização. Por exemplo, as recentes opções de racionalização das redes de serviços públicos (saúde, educação, tribunais, etc.) refletem uma aplicação insuficiente deste princípio como critério de referência na definição das soluções adotadas.

Ainda no âmbito do título I ("Princípios gerais"), o artigo 23.․ ("Extradição e expulsão") defende a não extradição e expulsão de cidadãos portugueses do território nacional, um aspeto que tem vindo a ganhar nova complexidade, nomeadamente com a multiplicação de situações de plurinacionalidade e de globalização de diferentes tipos de insegurança.

No contexto do título II ("Direitos, liberdades e garantias"), o artigo 44.. ("Direito de deslocação e de emigração") estabelece que a todos os cidadãos é garantida quer a livre mobilidade no interior do país, quer o direito de emigrar ou sair do país e de regressar. O estabelecimento do direito de deslocação e de emigração foi particularmente relevante face ao contexto político prevalecente durante o Estado Novo, caracterizado por fortes restrições, tanto sociais (por género, por exemplo) como políticas, à livre mobilidade dos cidadãos. Um novo significado ao objetivo e ao conteúdo do artigo 44 . $^{\circ}$ da Constituição de 1976 é conferido atualmente por fatores tão diversos como a criação do Espaço de Schengen (que assegura a livre circulação de pessoas dentro dos países signatários, no caso de Portugal desde 1991) e a multiplicação de programas da União Europeia de apoio à mobilidade de pessoas (de que o Programa Erasmus, nas suas diversas versões, constitui a principal referência), 
ou, com um significado totalmente distinto, a emigração induzida pelo recente contexto de crise e subsequentes medidas de austeridade ou a ascensão de nacionalismos acompanhada pela construção de barreiras e muros fronteiriços por governos que invocam questões de segurança face a possíveis ataques terroristas ou a fluxos incontrolados de deslocados.

No título III ("Direitos e deveres económicos, sociais e culturais"), o capítulo III, relativo a direitos e deveres sociais, inclui referências ao território mas atribui-lhe um caráter supletivo em relação a temas específicos: a habitação (artigo 65..$^{\circ}$ ) e o ambiente e a qualidade de vida (artigo 66..$^{\circ}$ ). No primeiro caso (habitação), o n. ${ }^{\circ}$ do referido artigo estipula que "Para assegurar o direito à habitação, incumbe ao estado", entre outros aspetos, "Programar e executar uma política de habitação inserida em planos de reordenamento geral do território e apoiada em planos de urbanização que garantam a existência de uma rede adequada de transportes e de equipamento social." No segundo caso (ambiente e qualidade de vida), o n.o 2 do artigo 66.. refere que "Incumbe ao estado, por meio de organismos próprios e por apelo a iniciativas populares", entre outros aspetos, "Ordenar o espaço territorial de forma a construir paisagens biologicamente equilibradas." Ou seja, o ordenamento do território não é apresentado de forma autónoma, como um objetivo em si próprio, mas antes como um meio associado a duas finalidades específicas: o direito a uma habitação condigna (artigo 65., n.. 1 ) e o direito a um "ambiente de vida humano, sadio e ecologicamente equilibrado" (artigo 66. ${ }^{\circ}$, n.. 1). Recorde-se que a Lei de Bases da Política de Ordenamento do Território e de Urbanismo (Lei n. ${ }^{\circ} 48 / 98$, de 11 de agosto) só viria a ser aprovada 22 anos mais tarde. Apenas com a aprovação desta lei ganha o ordenamento do território o estatuto de política pública autónoma.

Em suma, e no que diz respeito aos direitos e deveres fundamentais, o "território" merece uma menção explícita em cinco domínios: princípio da igualdade; extradição e expulsão; direito de deslocação e de emigração; habitação; ambiente e qualidade de vida. Importa ponderar em que medida as alterações políticas, sociais e culturais entretanto ocorridas, ou previsíveis a curto ou médio prazo, justificam tanto a introdução de alterações em alguns dos referidos artigos como a reinterpretação do seu significado e uma maior consciencialização das suas limitações e implicações. A atual versão da Constituição (VII revisão, 2005) irá dar uma resposta parcial a algumas das questões levantadas.

c) O território como referencial de planificação regional da organização económica O terceiro grande desígnio a merecer uma referência explícita à componente territorial diz respeito à planificação regional da organização económica, uma preocupação que foi ganhando força no âmbito dos diversos Planos de Fomento, ${ }^{1}$ sobretudo no contexto modernizador do período marcelista, e que agora recebe um novo estímulo a partir do conceito de planificação central então vigente nos designados países socialistas da Europa de Leste. Não surpreende, portanto, que a parte II ("Organização económica") da CRP76 
inclua diversas referências explícitas ao território, sobretudo na ótica do combate às assimetrias territoriais e da planificação regional da organização económica.

No título II ("Princípios gerais"), o artigo 81., sobre as incumbências prioritárias do estado, consagra dois dos seus 14 itens a questões territoriais: alínea $e$ - "Orientar o desenvolvimento económico e social no sentido de um crescimento equilibrado de todos os setores e regiões"; e alínea $i$ - "Eliminar progressivamente as diferenças sociais e económicas entre a cidade e o campo". Nos artigos do título III ("Plano") são diversas as menções explícitas ao "território" na sua dimensão regional. O n.․ 2 do artigo 91.․ ("Objetivos do Plano") refere que "O Plano deve garantir o desenvolvimento harmonioso dos setores e regiões" e "a justa repartição individual e regional do produto nacional". No n. 3 do artigo 94. ${ }^{\circ}$ estabelece-se que "O implemento [sic] do Plano deve ser descentralizado, regional e setorialmente, sem prejuízo da coordenação central, que compete, em última instância, ao Governo." Finalmente, no artigo 95. ("Regiões Plano") defende-se que: "1. O país será dividido em regiões Plano com base nas potencialidades e nas características geográficas, naturais, sociais e humanas do território nacional, com vista ao seu equilibrado desenvolvimento e tendo em conta as carências e os interesses das populações; 2 . A lei determina as regiões Plano e define o esquema dos órgãos de planificação regional que as integram."

Por último, no título IV ("Reforma agrária"), para além de outras menções implícitas a questões de natureza territorial, o artigo 98.o ("Minifúndios") salienta a especificidade que a reforma agrária deverá assumir em "regiões minifundiárias" de forma a adequar-se à dimensão das explorações ("integração cooperativa de diversas unidades", ou "emparcelamento ou arrendamento por mediação do organismo coordenador da reforma agrária").

Em termos genéricos, as menções ao "território" efetuadas na parte II ("Organização económica") da CRP76 prendem-se, sobretudo, com objetivos de políticas de desenvolvimento regional, então bastante valorizadas em todos os países europeus. Mas incluem igualmente objetivos de políticas que hoje designamos de coesão territorial ou de desenvolvimento rural.

d) O território como base de organização do poder político

Este é o quarto desígnio em que o "território" surge associado à CRP76. A parte III ("Organização do poder político") inclui as referências mais substanciais, tendo como objeto a organização do poder político: sistema eleitoral (título IV, artigo 152. - - "Círculos eleitorais"); regiões autónomas (título VII) e poder local (título VIII).

No que se refere ao título VIII ("Poder Local”), os artigos 238.. ("Categorias de autarquias locais e divisão administrativa"), 256. ("Instituição das regiões")

1 I Plano de Fomento: 1953-58; II Plano de Fomento: 1959-64; III Plano de Fomento: 1967-73 e IV Plano de Fomento: 1974-79. Este último nunca foi aplicado, dada a eclosão da Revolução de 25 de Abril de 1974. 
e 263.․ ("Distritos") são particularmente relevantes, não só pela importância atribuída ao papel e à democratização do poder local, mas também pelas interações que estabelecem entre si. As autarquias locais incluem as freguesias, os municípios e as regiões administrativas (artigo 238.ำ) e estas últimas devem corresponder às "regiões-plano" (artigo 256.ํ), estipulando-se que, enquanto as regiões não estiverem instituídas, subsistirá a divisão distrital (artigo 263. $\left.{ }^{\circ}\right)$. Na ausência da instituição de regiões administrativas, esta situação, a que entretanto se adicionou, em 1986, a adoção da nomenclatura das unidades territoriais para fins estatísticos (NUTS I, II e III) e, em 2008, a transformação das NUTS III em áreas metropolitanas e comunidades intermunicipais, tornou-se complexa e disfuncional: a coexistência, no Continente, de distritos, NUTS II / regiões-plano (CCDR) e NUTS III / áreas metropolitanas e comunidades intermunicipais cria uma relação pouco clara, em termos de legitimidade democrática e de eficiência da ação pública, entre representatividade política por via eletiva, planeamento desconcentrado da responsabilidade do governo e atribuições e competências comuns a municípios pertencentes a uma mesma NUTS III.

O capítulo V do título VIII ("Poder local"), sobre organizações populares de base territorial, é particularmente interessante à luz de tendências recentes de reforço da participação dos cidadãos ao nível local e comunitário. No artigo 264.ํำ ("Constituição e área") afirma-se o seguinte: "A fim de intensificar a participação das populações na vida administrativa local podem ser constituídas organizações populares de base territorial correspondentes a áreas inferiores à da freguesia." Essas organizações incluem duas figuras: a assembleia de moradores e a comissão de moradores. Independentemente do posterior historial de declínio desses dois tipos de organização popular de base territorial, nos últimos anos as práticas de mobilização, envolvimento e participação dos cidadãos nas políticas públicas e, de forma mais genérica, na vida pública têm vindo a ser estimuladas não só por instrumentos propostos pela Comissão Europeia e pelo Parlamento Europeu (por exemplo, as iniciativas de desenvolvimento local de base comunitária (DLBC), criadas para o ciclo de programação de fundos europeus 2014-2020), mas também como resposta a uma sociedade civil mais pró-ativa, tanto ao nível dos cidadãos como das associações de desenvolvimento local e territorial (ADLT) e outras organizações não governamentais de proximidade. Uma leitura conjunta das várias referências à dimensão "território" na Constituição da República Portuguesa de 1976 permite identificar a coexistência de aspetos de natureza distinta: aspetos clássicos, como os que dizem respeito ao território como elemento-chave da soberania nacional; aspetos modernizadores, que consagram temas e preocupações emergentes nos anos 60 (planeamento regional, acesso à habitação em áreas urbanas, ambiente e qualidade de vida); e aspetos inovadores ou mesmo disruptivos, como a instauração das regiões autónomas e do poder local. Vários desses aspetos virão a beneficiar, uma década mais tarde, da adesão de Portugal à então Comunidade Económica Europeia (1986), que contribuiu para "europeizar" princípios (subsidiariedade, coesão, desenvolvimento sustentável, etc.) e políticas (desenvolvimento 
regional, desenvolvimento rural, políticas urbanas, ordenamento do território, etc.), mesmo em domínios que não são da competência formal da União Europeia (cidades e ordenamento do território, por exemplo) (Costa et al., 2006; Alves, 2007; Ferrão 2010a, 2010b e 2014; Campos e Ferrão, 2015).

\section{Constituição da República Portuguesa de 2005: uma visão renovada do "território"?}

Através da comparação da atual Constituição da República Portuguesa (VII revisão constitucional, 2005) com a versão fundadora (1976) no que se refere a aspetos explicitamente relacionados com o "território" é possível identificar alterações ou aperfeiçoamentos, de que salientamos os que nos parecem mais significativos, num total de nove.

Em primeiro lugar, e no que se refere aos princípios fundamentais, o artigo 7.. ("Relações internacionais") passa a integrar o princípio da subsidiariedade e o conceito de coesão económica, social e territorial, associando-os à construção e ao aprofundamento da União Europeia. O alinhamento com princípios-chave do projeto europeu não podia ser mais claro.

Em segundo lugar, e ainda no âmbito dos princípios fundamentais, o artigo 9.. ("Tarefas fundamentais do estado") introduz como elementos novos as tarefas de "assegurar um correto ordenamento do território" e de "promover o desenvolvimento harmonioso de todo o território nacional, tendo em conta, designadamente, o caráter ultraperiférico dos arquipélagos dos Açores e da Madeira". A definição do ordenamento do território como tarefa fundamental do estado vai criar condições para que este domínio inicie um processo de autonomização enquanto domínio específico das políticas públicas.

Em terceiro lugar, em diversos artigos sobre direitos, liberdades e garantias pessoais (parte I, título II, capítulo I) são reforçadas as referências ao território nacional, nomeadamente através da introdução do artigo $33 .^{\circ}$ sobre expulsão, extradição e direito de asilo, um tema que virá a ganhar um relevo então insuspeitado nos últimos anos com a multiplicação de situações de mobilidade forçada e de fluxos diversificados de deslocados e candidatos ao estatuto de refugiado.

Em quarto lugar, e no âmbito dos direitos e deveres sociais (parte I, título III, capítulo II), o artigo 65. alarga a denominação inicial de "Habitação" para "Habitação e urbanismo", sendo adicionados dois novos pontos que incidem sobre questões relacionadas com instrumentos de planeamento e com leis de ordenamento do território e urbanismo (regras de ocupação, uso e transformação dos solos urbanos, expropriação de solos, participação dos interessados na elaboração dos instrumentos de planeamento físico e urbanístico). Esta alteração concretiza e reforça a definição inovadora do ordenamento do território como tarefa fundamental do estado anteriormente salientada.

Em quinto lugar, a ainda no âmbito dos direitos e deveres sociais (parte I, título III, capítulo II), o n. .92 do artigo $66 .^{\circ}$ alarga substancialmente a incumbência de o estado de "Ordenar o espaço territorial de forma a construir paisagens biologicamente 
equilibradas", consagrada na versão da Constituição de 1976, para "Ordenar e promover o ordenamento do território, tendo em vista uma correta localização das atividades, um equilibrado desenvolvimento socioeconómico e a valorização da paisagem." O conceito de ordenamento do território como política pública é, de novo, reforçado.

Em sexto lugar, e no que se refere aos princípios gerais de organização económica (parte II, título I), o artigo 81. ("Incumbências prioritárias do estado") contempla como elemento inovador a promoção da "coesão económica e social de todo o território nacional" e adiciona às diferenças "entre a cidade e o campo" as que ocorrem "entre o litoral e o interior". É, por outro lado, introduzido um novo artigo sobre o domínio público do estado, das regiões autónomas e das autarquias locais (artigo $84 .{ }^{\circ}$ ), onde se identificam os tipos de espaços a salvaguardar em nome do interesse público.

Em sétimo lugar, e também no contexto dos princípios gerais de organização económica, mas agora na parte II, título II, é possível identificar alterações significativas, aliás indiciadas pela modificação da epígrafe inicial de "Plano" para "Planos". O conceito de plano nacional é substituído pelo de "planos de desenvolvimento económico e social" (artigo 90. ${ }^{\circ}$ ), os quais podem integrar programas específicos de âmbito territorial e devem ser executados de forma regional e setorialmente descentralizada (artigo 91. ${ }^{\circ}$ ). Existe, claramente, um distanciamento em relação aos modelos de planeamento central prevalecentes durante décadas nos países socialistas da então designada Europa de Leste.

Em oitavo lugar, e de entre as diversas alterações incluídas no título III ("Assembleia da República") da parte III ("Organização do poder político"), duas merecem ser salientadas na ótica do "território": por um lado, o desaparecimento da referência aos distritos no artigo relativo aos círculos eleitorais (artigo 149.o.); por outro, a inclusão do regime geral de arrendamento rural e urbano e das bases do ordenamento do território e do urbanismo como matérias da exclusiva competência da Assembleia da República (salvo autorização ao governo) (artigo 165. ${ }^{\circ}$ ). Refira-se, em relação ao primeiro aspeto, que a única menção aos distritos que persiste na atual Constituição foi remetida para o artigo 291.․ incluído nas "Disposições finais e transitórias", e que estipula no seu n. 1 que "Enquanto as regiões administrativas não estiverem concretamente instituídas, subsistirá a divisão distrital no espaço por elas não abrangido."

Por último, no que se refere às regiões administrativas (parte III, título VIII "Poder local"), as alterações introduzidas, para além de deixarem transparecer o impasse em que a sua criação se encontra através do desdobramento do artigo 256. o ("Instituição das regiões") da versão originária da Constituição em dois novos artigos (255. - - "Criação legal"; e 256. - - "Instituição em concreto"), contempla um artigo adicional (258. - - "Planeamento"), que dispõe que "As regiões administrativas elaboram planos regionais e participam na elaboração dos planos nacionais."

Outras alterações foram, naturalmente, efetuadas nos domínios comentados na secção anterior relativa à CRP76. Mas as nove modificações assinaladas permitem destacar as seguintes mudanças: 
- um crescente alinhamento com princípios, prioridades e conceitos em vigor ou comummente utlizados no seio da União Europeia ou, em alguns casos, internacionalmente;

- o reforço da relação entre os temas "território" e "segurança";

- uma visão mais rica das assimetrias territoriais existentes no país;

- o reconhecimento das políticas e dos instrumentos de ordenamento do território e urbanismo como domínio autónomo;

- o reforço da intervenção do nível regional na elaboração de planos nacionais;

- a persistência de uma situação anómala em torno da não instituição de regiões administrativas e da persistência dos distritos enquanto elementos organizadores da territorialidade do poder político.

As alterações introduzidas não só atualizaram princípios e conceitos, como representam uma verdadeira mudança paradigmática: a substituição das tradições de planeamento regional e urbanístico, que mobilizavam instituições e comunidades técnico-científicas distintas e com escassa ou mesmo nula relação entre si, por uma visão mais ampla e integradora de ordenamento do território e urbanismo, que por esta via deixam de ser basicamente considerados como um meio visando outras finalidades (habitação; ambiente e qualidade de vida), conforme sucedia na versão originária da Constituição, para se constituir como um domínio autónomo.

Permanecem, no entanto, diversos equívocos e omissões no texto constitucional de 2005. Por exemplo, "território de origem" equivale a "território de residência"? Se assim for, o artigo 13.. ("Princípio da igualdade"), n.o 2, que estabelece que "Ninguém pode ser privilegiado, beneficiado, prejudicado, privado de qualquer direito ou isento de qualquer dever" em razão do "território de origem", deverá ser levado em conta em decisões públicas com impacte direto no quotidiano das populações locais, como sucede com a reconfiguração territorial das redes de equipamentos públicos? E por que motivo são as três componentes da coesão - económica, social e territorial - consagradas no artigo que se refere às relações internacionais / União Europeia (artigo 7. $\left.{ }^{\circ}\right)$, mas não no artigo que identifica as incumbências prioritárias do estado (artigo $\left.81 .^{\circ}\right)$, que omite a componente territorial?

\section{Constituição: um entrave a uma nova geração de políticas públicas de território?}

Serão as alterações introduzidas entre as versões de 1976 e 2005 da CRP suficientes para formular uma nova geração de políticas de território adequadas às prioridades e necessidades atuais e previsíveis? Ou, pelo contrário, essa nova geração exige a introdução de novas modificações, ainda que pontuais?

Comecemos por esclarecer o que entendemos por políticas públicas de território. Na verdade, esta expressão inclui dois grandes subconjuntos (Ferrão, 2015): 
as políticas explícitas, como, por exemplo, o ordenamento do território e as políticas de desenvolvimento territorial (regional, rural, urbano, local); e as políticas implícitas, isto é, as políticas que, sendo setoriais, estruturam fortemente o território pelos impactos que desencadeiam no que diz respeito ao seu uso, ocupação e organização: política agrícola, política florestal, política de transportes, política de conservação da natureza e biodiversidade, etc.

Quanto às restantes políticas, elas podem ser territorialmente cegas, ou seja, aplicadas de forma uniforme em todo o espaço nacional, ou parcialmente territorializadas, isto é, manterem a sua natureza setorial mas ajustarem algumas das suas componentes às particularidades de diferentes áreas do país (por exemplo, políticas de emprego, educação, saúde, etc.). A territorialização de políticas setoriais, quando existe, pode resultar de opções tomadas centralmente, ao nível do governo da República, ou decorrer de processos de desconcentração (órgãos periféricos da administração) e de descentralização (governos regionais e poder local).

Qual é, então, a relação existente entre a atual Constituição e as políticas de território, aqui entendidas de forma ampla: políticas de território explícitas, políticas de território implícitas e políticas setoriais parcialmente territorializadas?

Estando em jogo políticas muito distintas, não é possível apresentar uma resposta única e universal. Contudo, e em termos genéricos, parece legítimo afirmar-se que, dada a sua natureza e na sua versão atual, a Constituição condiciona mais o modo como as políticas de território são elaboradas e executadas do que, de forma direta, os seus conteúdos. Claro que a influência do modo como as políticas são elaboradas e aplicadas ("quem decide o quê") tem consequências significativas nos respetivos conteúdos. Mas a afirmação efetuada visa salientar que, em termos práticos, o principal ponto de articulação entre a Constituição e as políticas de território reside na organização do poder político, e (já) não tanto nos princípios, direitos, liberdades, garantias e deveres hoje constitucionalmente consagrados.

Este aspeto é sobretudo significativo no atual contexto de crescente "europeização" das políticas explícitas de território, mesmo em domínios, como o ordenamento do território ou as políticas urbanas, que não são da competência formal da União Europeia. Repartição vertical e horizontal de atribuições e competências, participação pública nas várias fases do ciclo de políticas (formulação, execução, monitorização, avaliação), governança multiescala e multinível, inovação institucional e modos colaborativos de decisão tornam-se, assim, os elementos-chave entre o conteúdo da Constituição da República Portuguesa e a existência de políticas de território com legitimidade democrática e aceitação social e que, ao mesmo tempo, sejam eficientes e justas. Alguns destes aspetos necessitam do respaldo do texto constitucional, eventualmente clarificado em aspetos pontuais. Mas, para a maior parte deles, a Constituição, na sua atual versão, é relativamente neutra. 


\section{Pensar o futuro: questões a colocar, aspetos a debater}

Face ao conjunto de observações anteriormente apresentadas, e dada a diferente natureza das diversas políticas de território e das entidades por elas responsáveis, importa debater e aprofundar algumas questões:

- Em que medida são as atuais políticas explícitas e implícitas de território, bem como os processos de territorialização de políticas setoriais, condicionados, positiva ou negativamente, pelos diversos aspetos consagrados na Constituição (princípios, direitos, deveres, instrumentos, organização do poder político, etc.)?

- Garante a Constituição, na sua atual formulação, as condições para conceber uma nova geração de políticas de território e de processos de territorialização de políticas setoriais sensíveis à diversidade territorial do país?

- Podem essas políticas e esses processos concretizar-se de forma democrática, eficiente e justa tendo por base as garantias conferidas atualmente pela Constituição?

- São a crescente "europeização" das políticas de território e o aumento da sua exposição a agendas globais (alterações climáticas, segurança internacional, globalização económica, etc.) compatíveis com a atual Constituição?

Estes são exemplos de questões que importa debater e aprofundar, para garantir uma relação virtuosa entre o potencial presente na versão em vigor da Constituição da República Portuguesa e a formulação e concretização de políticas de território democráticas, eficientes e justas.

\section{Referências bibliográficas}

Alves, Rui (2007), Políticas de Planeamento e de Ordenamento do Território no Estado Português, Lisboa, Fundação Calouste Gulbenkian e Fundação para a Ciência e a Tecnologia.

Campos, Vítor, e João Ferrão (2015), “O ordenamento do território em Portugal: uma perspetiva genealógica", ICS Working Papers, 1.

Costa, Eduarda Marques da, Jorge Gaspar, José Manuel Simões, e Sérgio Barroso (2006), "Ordenamento do território", em Carlos Albero Medeiros (dir.), Jorge Gaspar e José Manuel Simões (coord.), Geografia de Portugal, volume 4: Planeamento e Ordenamento do Território, Lisboa, Círculo dos Leitores, pp. 259-343.

Ferrão, João (2010a), “Uma visão política da evolução da política de ordenamento do território", em Juventude Socialista (org.), Socialismo no Séc. XXI, Lisboa, Esfera do Caos, pp. 62-79.

Ferrão, João (2010b), “Ordenamento do território: 25 anos de aprendizagem”, Europa. Novas Fronteiras, 26-27, pp. 77-84.

Ferrão, João (2011), O Ordenamento do Território como Política Pública, Lisboa, Fundação Calouste Gulbenkian. 
Ferrão, João (2015), “Ambiente e território: para uma nova geração de políticas com futuro", em Viriato Soromenho-Marques e Paulo Trigo Pereira (orgs.), Afirmar o Futuro. Políticas Públicas para Portugal,volume II: Desenvolvimento Sustentável, Economia, Território e Ambiente, Lisboa, Fundação Calouste Gulbenkian, pp. 328-336.

João Ferrão. Instituto de Ciências Sociais, Universidade de Lisboa, Av. Prof. Aníbal de Bettencourt, 9, 1600-189 Lisboa, Portugal. E-mail: joao.ferrao@ics.ulisboa.pt 